European journal of American studies

\title{
Creating a Coyote Cartography: Critical Regionalism at the Border
}

\section{Caleb Bailey}

\section{OpenEdition}

\section{Journals}

Electronic version

URL: https://journals.openedition.org/ejas/10396

DOI: $10.4000 /$ ejas. 10396

ISSN: 1991-9336

Publisher

European Association for American Studies

Electronic reference

Caleb Bailey, "Creating a Coyote Cartography: Critical Regionalism at the Border", European journal of American studies [Online], 9-3 | 2014, document 1, Online since 23 December 2014, connection on 08 July 2021. URL: http://journals.openedition.org/ejas/10396 ; DOI: https://doi.org/10.4000/ejas.10396

This text was automatically generated on 8 July 2021 .

Creative Commons License 


\title{
Creating a Coyote Cartography: Critical Regionalism at the Border
}

\author{
Caleb Bailey
}

\section{Coyote Cartography}

1 Borders and borderlands are always already transnational: regions where nations meet and intermingle. North American borders, despite the blending of cultures which occurs in these zones, are dominated by discursive constructions which emphasize, and emanate from, the ideological edifice of nationhood built by but one of the three nations of the continent: the United States. The U.S. boundary with Canada, we are told, is the longest undefended border in the world, often barely visible; its border with Mexico, we can see, is an intensely defended and increasingly physical barrier. These borders have markedly different psychological functions on either side of the cartographic marks which delineate the continental United States. The view from Mexico differs from that north of the line: the border a wall separating people from families, traditions, and ancestral lands all annexed in the midnineteenth century. For many Canadians the $49^{\text {th }}$ parallel performs an important psychic role in defining an identity distinct from that south of the line; the border is an important line of cultural defense. Even from these external perspectives, then, the border performs a significant role in notions of nationalism, as it does from the perspective radiating from the central nation of North America.

2 Such centripetal appropriations of distinctly transnational regions by singular national concerns need to be reconfigured if regionalism is to be extricated from its relationship with nationalism. Two recent fieldshaping studies point the way in this regard, informing the development of my own arguments here and offering new theoretical maps which 
suggest ways in which centrifugal readings might be developed to interrogate regions like those found at national borders: regions which appear simultaneously cartographically distinct yet also culturally indistinct. Claudia Sadowski-Smith's Border Fictions (2008) suggests two ideas of particular pertinence to this essay. Firstly, that studying fiction which emerges from border regions can enable us to "move beyond dominant conceptualizations of who inhabits and can speak for the border" (11). And secondly, in doing so, that "an alternative interAmerican framework that focuses on...borders...places into dialogue hemispheric approaches to these geographies" (17). In focusing on marginalized voices-indigenous, Chicano/a, Asian-Sadowski-Smith effectively complicates borders as demarcations of singular identities. Likewise, in developing a comparative hemispheric framework, her analysis transgresses both national and firmly entrenched disciplinary boundaries. Her provocative suggestion that “'American studies' has long uncritically appropriated the name of the entire hemisphere for one particular country" (19)-in much the same way as that same country dominates many existing border discourses-is one that my arguments herein will respond to.

з Of equal importance to my approach is Neil Campbell's The Rhizomatic West (2008) and its development of critical regionalism as an innovative and apt lens to reorient analyses of the U.S. region of the West in-as the subtitle of his book suggests-a "transnational age." Critical regionalism-originating in the theory and practice of architecture-has gained a significant critical foothold in Postwestern Studies (the area in which Campbell predominantly works); it is a field which, Krista Comer has recently remarked, "often gestures...toward a mood, a condition, a sense of place and people as disembedded or deterritorialized" (10). Herein, the use of "deterritorialization" as a key tenet of her discipline signals the growing importance of Deleuzian theory in new conceptions of regions such as the West. This is further denoted in the central (dis)organizing principle of Campbell's book in its aggregation and deployment of the Deleuzian metaphor of the rhizome (an organism characteristic of grasses which often have haphazard distribution) as complementary to the critically regionalist goals of his project. Campbell's addition of the rhizomatic to the critical regionalist frame succeeds in a number of unforeseen, if not unexpected, ways.

4 Kenneth Frampton's influential essay "Towards a Critical Regionalism: Six Points for an Architecture of Resistance" (1983) is the most oft-cited originating point for the theory named in its title. Frampton proposes that architecture should attempt to negotiate between the global and the local: "mediat[ing] the impact of universal civilization with elements derived indirectly from the peculiarities of a particular place" (21). Material structures thus become sites of dialogue that reconcile the seeming contradiction of being both global and local: in simultaneously having walls that contain an inside and windows that enable an outside. The rhizome-which Deleuzian philosophy invokes in 
opposition to the rootedness of arboreal (tree-like) approaches to organizing knowledge and understanding-has 'roots' but also travels 'routes,' and is open to the outside in ways that epitomize the goals of critical regionalism as a dialogical approach to regionalism.

5 If, as Campbell's work demonstrates, the Deleuzian conception of the rhizome is one way in which regionalism might have its boundaries transgressed and reconfigured, how might critical regionalism probe further beyond the edges of regionalism if we add another Deleuzian concept-the figure of the nomad and related nomadic thought-to its theoretical framework? The nomad, in Deleuzian terms, exists in the smooth space between the striated spaces which borders-and the states that police them-construct and maintain. If we think nomadically, positioning ourselves in these in-between spaces, we can speak to the multiple positions which borders construct and avoid the hierarchical and binary structures with which regionalism-in its subservience to nationalism-seems inextricably bound. Furthermore, such an approach fosters the dialogue critical regionalism envisages, a critical conversation between the two borders at the northern and southern boundaries of the United States, a redrawing of the critical and theoretical maps which scholars use to navigate discourse on the border and its borderlands, and which I call "coyote cartography."

${ }_{6}$ Coyote exists at both borders-as a trickster figure in indigenous Canadian literature and as a people smuggler in Mexico. To employ these coyotes nomadically beyond the borders with which they are most often associated brings them into dialogue with each other, making our theoretical maps of the border broader and more interconnected in their scope. In this way coyote cartography seeks to uncover and decipher "an uncontainable symbolic geography of relations, [a] creative terrain on which minority subjects act and interact in fruitful ways" (Lionnet and Shih 2). The geography which a coyote cartography traces, then, is one in which readings of the coyote who is employed by undocumented migrants is reinscribed as a trickster figure, and Coyote the trickster is read in the opposite configuration: as a smuggler of undocumented understandings and perspectives, and of new theoretical stances that can be adopted when analyzing indigenous literature.

7 Should my deployment of indigenous tricksters within a EuroWestern philosophical frame be read as a recolonizing gesture, I would point to some works by indigenous scholars and writers which both echo and enhance the arguments I put forward in this essay. Firstly, while my re-reading of Coyote relies, predominantly, upon Western academic and anthropological discourse, it nonetheless echoes elements of the trickster as it occurs in tribe-specific cultures and understandings. For example, Neal McLeod (Cree) points to a triballyspecific imagining of the trickster "which denotes the notion of an older brother...assum[ing] a state of kinship" (97). This "kinship" is effectively supported and transported by coyote cartography through its own seeking out of relational moments in borderlands discourse across, 
between, and through, separate and disparate geographies. Additionally, McLeod quite rightly queries the use of the word trickster to denote the figure, noting that "[t]he concepts centred [sic] on the word in English include such words as 'trickery,' 'tricky,' and 'trick,' which indicate something less than the truth" (97). Etymologically, this is a moot point; however this very possible absence of veracity in Western interpretations of the trickster can nonetheless be aligned with the overarching goals of this piece: recognizing the real-and-imagined nature of the border, locating its fictions and rearticulating them.

8 Following the theme of kinship, Tol Foster (Anglo-Creek) has argued for a "relational regionality" as a starting point for Native American literary studies. Foster welcomes possible interventions in this field that stem from certain Euro-Western critics-particularly Foucault and to a lesser, though no less interesting extent, Patricia Nelson Limerick and George Lipsitz-that pay "[a]ttention to specificity, locality, and contingency": three key tenets of critical regionalism that inform my approach (267). Whilst Foster suggests that such approaches cannot adequately provide "some theory that will liberate and explain indigenous people," this is not my purpose here (ibid.). Replacing tribally-specific approaches with more regional ones, Foster suggests, leads "to a very different reading of some...material than now exists in the scholarship": an outcome more akin to my approach (270). Remaining cognizant of locally specific epistemologies does not preclude, in Foster's own terms, "imagining them as our relations" (275). As my proceeding analysis will demonstrate, the possible relationship between Coyote and coyote is a longstanding but underexplored one.

9 One further corrective: as Deanna Reder (Cree-Métis) reminds us in her preface to Troubling Tricksters, the term trickster "is the invention of a nineteenth-century anthropologist," and we should also remember that "the Anishinaabeg told stories about Nanabush, the Cree told stories about Wesakecak, the Blackfoot told stories about Naapi, [and] the Stó:lō told stories about Coyote" (vii). As such, the critical map that I sketch here is but one of any number of cartographies that might be drawn when we interrogate regional constructions across time, space, and borders.

\section{Smugglers and Tricksters}

The late Canadian poet and writer Robert Kroetsch suggests that writers might "choose to be Coyote" (99). This is a provocative and informative observation that hints at the emergence of what some critics have labeled "coyote aesthetics" in the writings of several indigenous and non-indigenous authors, a style which "has at its heart fragmentation, deconstruction and a refiguration of ideas that stretch beyond Western conceptions" (Macpherson 182). If such deliberately disruptive tactics exist within the texts we might seek to analyze in an 
exploration of border discourses, then a new interpretive mode which mirrors this disjunctive and challenging material must be developed. If the author can become Coyote, can the critic become the same? Scholarly writings on both the Canadian and Mexican borderlands are replete with calls for the creation of just such strategies. Kroetsch's call for the adoption of a trickster persona is based upon his own singular understanding of what Coyote represents. If a definition of what this figure and its functions represent were expanded to take in other traits, there would be abundant opportunity for developing innovative analytical stances from which to interrogate cultural constructions of border territories. Consider the biological version of coyote-Canis latrans-for instance: an animal distributed across the North American continent and one that crosses borders without impediment. Considering coyote's canid cousin, the wolf (Canis lupus), Karen Jones suggests that "learning to think like a wolf might...be useful, at least in allowing us to see the fictions and fixtures of the border," precisely because of the differing ways in which this creature is viewed on both sides of the $49^{\text {th }}$ parallel (348). Arguing that such "movement patterns... [operate] without thought to the border patrol," Jones posits that embracing a similarly defiant persona "allow[s] for a productive comparison of frontier cultures and attitudes" (338). And what of the other frontier under consideration here? If, as Jones speculates, a member of the animal kingdom can "become political," then exploring the deeply political actions of the coyotes employed by those seeking to cross the Mexican border into the United States reveals further ways in which assuming elements of this other coyote might also interrupt traditional border discourses and their interpretations (347). Coyote the smuggler is a complimentary figure in this regard since, as Pérez-Torres notes,

[t]hose involved in the articulation of minority discourses of all kinds act like coyotes, smuggling across national, disciplinary, and methodological boundaries....agents who already challenge the significance of those boundaries. (823)

11 Considering some of the biological and behavioral characteristics of the genus Canis latrans, Bright notes that "coyotes have their home burrows but may range widely," leading to an increasing dispersal of the animal across the North American continent (34). Such diffusion of the species and their haphazard distribution seems reflective of much Western discourse on the mythological counterpart who displays "an uncontrollable urge to wander" (Radin 165). Additionally, much anthropological analysis of the Coyote trope focuses upon the links between the animal's predatory instincts and cunning, and, according to Harris, their translation into the "trickery, thievery and creativity" that is often on display in indigenous storytelling (qtd. in Spener 90).Similarly, the coyotes employed by those seeking to cross the U.S.Mexico border illegally gain such an epithet as it "refers to the wily ways of the[se] smugglers" (Martinez 27). There may be similarities between the origins of these twin deployments of the Coyote/coyote 
trope, but their modern-day incarnations-in myth at the United States' northern border, in illegal action to the south-and the strategies that they employ in both guises display a marked but subtle difference.

${ }_{12}$ Coyote as a people smuggler is just the latest in a long line of invocations of the Mesoamerican mythic trope. Indeed, as Spener notes in his account of the relationship between smuggler and smuggled, coyotes and the services they provide-coyotaje-are commonplace; their employment by others is very much an everyday occurrence. Generally employed to assist, illegally or otherwise, a person's passage through the bureaucracy of everyday life in Mexico, the coyote is not merely involved in illegal migration but also acts as labor broker, forger, and counterfeiter, a go-between or middleman. As such, a Mexican coyote is rarely an individual but a member of "a loosely knit network in which different individuals play different roles" (Spener 91). Such coyotaje practices are key to the low-level resistance enacted "by the disinherited members of Mexican society" (96). They function to combat exclusion from power and wealth in a way suited to people of a mestizo/ mestiza ancestry or identity. Thus it is little wonder that coyote has begun to feature heavily in such non-indigenous society and culture, whose mestizaje identity is marked by hybridity and constantly negotiated. As Wolf notes, "the ever-shifting nature of the social conditions" that the mestizo/mestiza is often subject to, forces them "to move with guile and speed through the hidden passageways of society," never committing themselves to a particular site or territory (qtd. in Spener 96). Indeed, the term coyote is also used, in similarly everyday circumstances to its illegal operative namesake, as a racial category discernible in much the same way as mestizo/mestiza, by hybridity. These unstable categorizations and imaginings of terms etymologically related to manifestations of coyote are reflective of the folkloric origins of coyote as an ephemeral, almost temporary presence, "the one that runs from one town to another and belongs to neither" (Hyde 6). Here we move towards the use of coyote that I aim to employ, a figure of constant motion: a nomad.

${ }_{13}$ Coyote as the trickster figure, often found at play in indigenous Canadian literature, is a similar shaper and creator of such power relations, but operates in subtly different ways. Where the Mexican coyote is a literal cultural actor involved in negotiating a way through the striated space of the state, the trickster Coyote constitutes a mythic archetype more often found in the smooth spaces between the striae of such state spaces. Gerald Vizenor, the prominent Anishnaabe writer and theorist, claims that such trickster figures represent and enact "a 'doing' in narrative points of view and outside the imposed structures" (13). This clearly demonstrates Coyote's lack of subservience to striated space-which he exists outside of. But what Vizenor's adjectival naming of Coyote's behavior also does is to note its creation as processive, as always shifting, always moving. Just as Canis latrans inhabits the entire North American continent, so too does its mythological trickster 
counterpart: they "are not 'rooted' to a specific place but are linked to a wider area or region," further enhancing the inherent mobility of "these so-called culture heroes ... identified by their wanderlust" (Eigenbrod 165). The identification of such itinerant traits mirrors the deterritorialization of the nomad and, once more, ties the figure back to its biological forebear, for, like the Deleuzian principle of the rhizome itself, Canis Latrans is always "moving with a certain stealth [and is] powerful in its dispersion" (Kaplan 87). Hence, they resist incorporation into the striated space of the state through which they roam. In this roaming, "[t]he life of the nomad is the intermezzo," the in-between (Deleuze and Guattari 380). In this sense, the Mexican coyote whose principal folkloric trait is identified as a fundamental "in-betweenness" (Spener 100) can be aligned with the indigenous Canadian configuration of Coyote, wherein it functions as "a figure of 'open interrelationship' between radically different 'worlds'” (Davidson 93). Coyote/coyote, we might say, is always between points of striated space -of the gridded and geometrical-and is therefore able to gain access to the nomadic smooth space, wherein the chosen trajectory which the nomad constantly travels "give[s] that space its peculiar quality" (Colebrook 66-67). The "peculiar qualities" of a coyote cartographic space that both tropes occupy are those in which such smooth spaces are overwritten, palimpsest-style, over the striations which border regions represent: as Davidson suggests in his readings of Canadian prairie fictions, "Coyote took smooth, straight rivers and made them twist and turn" (198).

${ }_{14}$ Our theoretical approach must mirror the "disjunctive, disruptive, and potentially radically subversive" (Smith 59) characteristics of the mythological trickster Coyote, and we must also adopt the persona of the coyote at work in the Mexican borderlands, a vehicle for "migration...evasion...and clandestine crossing" of territorial and theoretical boundaries (Spener 87). By making both Coyote and the coyote nomadic subjects, the different interpretations, deployments, and territories of these figures might be inverted and applied to their borderland opposite, making them both specific and localized but also interrelated. Herein we might push the limits of culture and the borders that nominally restrict them and effect, as Michaelson and Johnson suggest, a theory based upon

travelling logics [which] can give way to...a recognition that cultural borders are effects produced in the mental operation that pulls two groups of people together...

(con)fusing them, in order to contrast them. (9)

Vizenor elucidates the function of Coyote in this regard when he states that "[s]ilence and separation...are the antitheses of [the] trickster," and that this sign "wanders between narrative voices" (13). These observations cut to the very heart of the need for coyote cartography as a means by which we might decenter American Studies, bring the "margins" of North America-Canada and Mexico-more sharply into view, and allow a series of critical and theoretical gestures and exchanges to develop between them. Here we can replace "silence" 
with dialogue between the real-and-imagined statuses of these two borders, through the real-and-imagined figures of Coyote and coyote. Thus we can offer a vital divergence from regionalist discourse that takes no account of moments of convergence in the lived and cultural experiences of specific but separate regions. If regionalism elides difference and striates space, the reinstatement of indigenous voices, rendered silent by the ideological appropriation and configuration of the physical and psychical borders erected around and between them, can subvert these spaces and make them smooth once more.

16 This location, dislocation, and relocation of Coyote/coyote mirrors the de- and re-territorializing functions of Deleuze and Guattari's notions of nomadism and nomadic thought. Krista Comer, in reviewing developments in both critical regionalism and post-regionalism, suggests that "it might be advantageous to begin and remain critically deterritorialized" in order to establish "critical footing via other genealogies" (5). This is effectively achieved here as the deployment of a coyote cartography not only creates a smooth geographical space, less subject to the imposition of the striations of the nation-state. Coyote cartography also creates a smooth theoretical space in which, in common with the rhizome, pertinent elements of a diverse range of disciplinary methodologies and their insights might reveal themselves and offer new ways in which to approach border discourses. The discursive constructions of border regions which this essay now moves on to consider come from the work of Thomas King and Charles Bowden.

\section{Thomas King}

Thomas King's fictional works often deconstruct borders, burrowing into the spurious foundations on which they are built and destabilizing the privileged subjectivity they claim to represent. Key here is the recognition-not explicitly stated by King himself, but certainly readable in his work-that any border has a dual identity. As New attests, "[t]here is borderline...and there is borderland. The one names and divides; the other is psychic, indeterminate" (4). Further, we might suggest, a borderline is a geographical demarcation and cartographic mark which one might experience physically—a putative "reality" —and a borderland is a psychological territory experienced mentally-an "imaginary" landscape or a place and a space which are both constructs. These constructs exist in an interdependent relationship where one-the borderline-“construct[s] conceptual edges," and the other-the borderland- "construct[s] territories of translation" (New 4).This territory-in the works of Thomas King, predominantly the Alberta-Montana border region-might provide the site for the translation of Coyote into coyote, and, simultaneously, afford the opportunity to probe the edges of the critically regionalist-inspired coyote cartographyconcept outlined here. King's own literary 
constructions of these real-and-imagined border regions reflect New's suggestion that such zones are "symptomatic of...a condition of 'interstitiality,' in-betweenness, [and] an experiential territory of intervention and revision," and, as such, provide the setting in which we might not only translate Coyote but also revise the function of this figure and explore what such an intervention might reveal (27).In this way a coyote cartography practice proceeds in a clearly critically regionalist manner, for, as Frampton proposes, a structure inspired by critical regionalism ensures that "meaning stems from a revealed conjunction between" (22). This conjunction is not only that between the two coyote tropes but also between those real-and-imagined border regions which King and others construct in their narratives.

18 Whether reading borders as lines or lands, real or imagined, striated or smooth, Canadian or American, indigenous or colonial, King's writing erases the dichotomous, disjunctive "or" and replaces it with the conjunctive "and." In doing so, and in speaking of and to both positions, the physical and psychical borders of King's narrative settings reinstate the articulating function of the "joint" between the two nation-states which the boundary at the $49^{\text {th }}$ parallel represents-granting it the ability to articulate not only its geographical permeability and malleability, but also its imaginative expository function. Furthermore, such re-articulations present opportunities for a reading of the border "in terms of a north-south rather than east-west axis," which the latitudinal function of the arbitrary boundary between Canada and the United States subtly encourages (Pérez-Torres 816). In re-orienting the axis of interpretation to north-south-especially in a study of America in its hemispheric context-a critique of North American borders which are predominantly traversed physically, following these alternative compass points, is better placed to equate experiences of these cartographic hierarchies. Such a critique also opens border studies to José David Saldívar's call for "finding historical, ideological and cultural simultaneity in the imaginative writings of the Americas" (22). This is the fundamental purpose of coyote cartography: seeking simultaneity in the real-and-imagined statuses of border regions through the inversion of the coyote trope.

19 The story "Borders"-appearing in One Good Story, That One (1993) -is perhaps Thomas King's most critiqued piece of short fiction.Given its potent political dimension, rendering of literal border-crossing discourse as humorous, if not faintly ridiculous, and insistence upon Native authority in matters of identity and citizenship, this is no surprise. With its narrative centering on a border crossing facilitated only through the evasion and subversion of border bureaucracy, what is surprising is that the "illegality" of these tactics has not formed part of the critical discourse. Furthermore, existing analyses do not include recourse to the protagonists' matter-of-fact deployment of these strategies, nor to the fact that they are presented as everyday occurrences. "Borders" is narrated by a Blackfoot boy as he and his 
mother attempt to cross the border in order to visit his sister Laetitia in Salt Lake City. At the border, when asked to declare their citizenship as either "Canadian" or "American," the mother character will only answer "Blackfoot." As a consequence they are unable to either enter the U.S. or return to Canada and find themselves sequestered at a duty-free store in the space between the two nations.

20 The consistency of existing interpretations of "Borders" presents something which could be seen as making instantly problematic my insistence upon a "nomadic" mode of thought to open up the boundaries of critical regionalism. The interstitial setting of much of the narrativea duty-free shop in the zone between Canada and the United Stateshas been claimed as a territory where King himself critiques the trend for triumphal readings of the figure of the nomad as a cultural agent not subject to the imposition of identity by the nation-state. Peters, for example, writes that in

relegating his protagonists to the Duty Free zone between Canada and the US, King challenges the post-modern celebration of Western identities as decentered and nomadic. (196)

21 Yet, I would argue, this setting, by its very nature-in-between two nations-offers only the temporary territorialization which the nomad makes; certainly, the older female character's acceptance of this situation-"my mother seemed in good spirits, and, all in all, it was as much an adventure as an inconvenience"-speaks not of disenfranchisement but of an understanding that this territory is only temporary (King, "Borders" 141). This space provides a setting in which the bricolage of identities present in thecharacters, and within these same characters, are not decentered but are able to claim a new and revitalized centrality within the margin they are forced to occupy. The "tiny" flags worn by the store's clerk diminish the dominant position of the two nation-states in understanding what the territory represents (140). Additionally, with the boy and his mother now the predominant population of the borderland in which the store is situated, this marginal territory is reclaimed, both physically and psychically, as Blackfoot land, bridging the border which arbitrarily bisected the nation of which they claim citizenship. The indigenous lineage which the maternal character insists upon redraws the cartographic hierarchy present at the border. As one border guard remarks: "I know that we got Blackfeet on the American side and the Canadians got Blackfeet on their side'" (135).The characters' attempt to evade the bureaucracy of the border collapses this opposition and recreates the smooth space which the nation-state attempts to draw its own lines across.

22 If we were to transgress the borders of the narrative of "Borders," to look beyond the few pages in which King constructs this dynamic border discourse-to proceed nomadically in our reading of the text by viewing it as merely one point along a relay, a temporary territory for interpretation-we could build further this notion of the author and his characters as smugglers, as coyotes. Recourse to King's The Truth About Stories: A Native Narrative (2003) is hugely informative in this 
regard. To comprehend further the complex interweaving of the borderland and the borderline in "Borders," tracing a line-of-flight to the essay "What Is It about Us That You Don't Like?" in this volume, highlights the cultural agency enacted by King's characters and the bureaucratic measures their attempts to cross the border also subvert. Justification for this is contained in a simple "disguise" worn by one of the characters that eventually helps to facilitate the protagonists' eventual crossing of the border:

Around noon, a good-looking guy in a dark blue suit and an orange tie with little ducks on it...talked to my mother for a little while, and, after they were done talking...we got into our car. ("Borders" 143)

The car drives to the border a final time, and, having declared once more their citizenship as "Blackfoot," they are finally allowed to cross into the United States, their identity as Blackfoot intact. Significantly, this exchange is preceded by the boy's mother spending the night in the duty free store parking lot telling stories about Coyote. The framing device King uses in "What Is It about Us That You Don't Like?"-an essay dealing in part with legislation "that can make Indians disappear in a twinkle" (Truth 132)-is a "Coyote stor[y]...one of my favourites [sic]...the one about Coyote and the Ducks" (122).

24 The story King weaves here has Coyote convincing the ducks to slowly give up their feathers-ostensibly to keep them safe from "Human Beings"-so he might have a coat to rival that of fellow trickster Raven (Truth 125). The slow but inexorable march towards the point at which the ducks have been stripped of all of their feathers-of their very identity-mirrors what King goes on to explicate about the various pieces of legislation developed both in Canada and the United States to similarly strip Native people of their land, their rights, and their identities. King decries the many pieces of legislation that have been created by both the Canadian and American governments-most often with the aim of assimilating the Native and clothed in paternalistic rhetoric-in a complex polemic which wanders with righteous anger between the two nation-states and the bureaucratic machinery enclosing the protagonists in "Borders": The Indian Act (1876); The General Allotment Act (1887); The Indian Reorganization Act (1934); The Termination Act (1953); and Bill C-31, Amendment to the Indian Act (1985).

${ }_{25}$ Hence, in reading outside the linearity of the narrative, between two separate writings, across a north-south rather than east-west axis, the act of defiance at the border in the short story attains a much larger significance: it is no longer just "a legal technicality" that detains the Blackfoot pair in the liminal no-man's-land between the borderline ("Borders" 136). Rather, their eventual passage across the physical boundary between Canada and the United States becomes a multifarious act of evasion within the narrative and a multifaceted act on the author's part; a smuggling in to the fiction of a number of undocumented intertexts which add to the psychic borderland which the boy and his mother must negotiate. The catalyst for this negotiation 
-whereby the Blackfoot identity remains intact even as it evades the legal machinery of the state-is the man with the duck-adorned tie. Is he Coyote? There is no trickster behavior to detect in his actions. More likely, this is the Blackfoot actors' coyote, his tie a simple reminder for the mother (and the reader) that "like the Ducks in the Coyote story... Indians had to give up most of their feathers in order to keep some of their feathers for themselves" (King, Truth 129), and that to do so again, to acquiesce to the bureaucracy of the border-which would enable a more speedy crossing of the borderline-would be to become another occupant of the borderland of history and tragedy which King outlines in his examination of the various "Indian" legislation. In this regard, the mother character seems to personify the legal counsel for the Sawridge, Tsuu T'ina, and Ermineskin First Nations of Alberta who, in response to Bill C-31, stated: "It's not just where you draw the line... but who draws the line" (qtd. in King, Truth 150). The Blackfoot mother character in "Borders" expands this cartographic border analogy yet further, erasing both borderlines and redrawing them in a fashion which displays traits that have more in common with coyote than Coyote.

${ }_{26}$ My analysis of King's fiction demonstrates the possibilities of coyote cartography as a non-hierarchical means of critique that, through the re-inscription of Coyote as coyote and practitioner of coyotaje, enables us to develop a critically regionalist method in which the global-local nexus of regional cultural production is brought more sharply into focus. Furthermore it re-draws not only the spatial limits of regions but also their temporal limits through the transgression of textual boundaries: "Borders" thus becomes not only a text that challenges the notion of the spatial limits that national boundaries represent but also one that, through the re-insertion of inter- and intratextual elements, speaks directly to the aims and functions of critical regionalism as both a theoretical framework and a socio-cultural reality that demands and effects a complex mediation between the supposed binary of past and present.

27 Where this routing of regional archetypes envisaged Coyote as coyote, its primary function was one of re-inscription, a means by which new readings might be realized and new avenues for interpretation might emerge. To invert this trajectory-to disrupt any notion that this is another, merely differentiated, hierarchy-and to read coyote as Coyote requires less a re-inscription and more a reinstatement: a reinstatement of the origins of the folkloric and mythological functions of Coyote within the territory of Mexico. Since those who assist undocumented Mexican migrants to cross the border into the United States first came to be popularly known as "coyotes" in the 1920s, these origins have been increasingly marginalized-if not lost altogether-in articulations of the geopolitical power struggle of which they are an integral part. The concern encapsulated here is one of miscegenation: suspicions about what the mixing of cultures-in whatever form-might represent to the United States. One need only think of the avaricious 
nature of the villainous Wile E. Coyote as he pursues the innocent and blithely unaware Roadrunner in the popular Warner Brothers cartoon to see a reflection of the creature that approximates the mainstream opinion of what undocumented migration means to U.S. society. Yet, Coyote in its mythological incarnation appears to have vanished from much of the critical thinking and analysis directed at the Mexico-U.S. border and its discursive representations. Here, the entrenchment of a set of geopolitical ideologies and militaristic rhetoric has rendered the relationship between coyote the people smuggler and Coyote the trickster virtually extinct. Coyote, as found in many popular articulations of the ongoing struggle by elements within the United States to shore up its southern border against "the exportation of brown flesh to the United States," becomes simply a pejorative, a linguistic device which serves only to shore up the imaginative ideological border which is also imagined to require patrolling (Bowden 1). This fact reflects, to some extent, a trend noted recently by Marta Carminero-Santangelo, who argues that the discursive construction of such "illegals" and "aliens"

suggests the degree to which this population has been narratively constructed as not fitting into the boundaries of the American 'nation'-indeed, as fundamentally threatening that nation. (158)

The role of coyotes would seem to me to be a primary element of such narratives, even more so when we consider that their role in such border-crossings relies upon their erasure of both the physical and psychical manifestations of the border between nations. In addition, the narrative construction of coyotes within much of the literary journalistic discourse that Carminero-Santangelo critiques is similarly focused almost exclusively on their "threatening" behaviors, both towards the integrity of the nation, its borders, and to the "pollos" who employ them. Such skewed rhetoric also belies the original meanings of both Coyote and coyotaje, which are inextricably bound to the figure of the coyote and their modus operandi: "it is at well-guarded barriers that these figures are especially tricksters," Hyde reminds us, "god[s] of the threshold in all its forms" (7-8).

29 This erasure of the trickster functions and origins of the coyote and its coyotaje belies the very etymological roots and subsequent deviations of the word coyote. Originating in the Nahuatl dialect as coyotl-meaning "to make a hole or dugout" - the biological coyote was, it has been suggested, so named for its perceived "swiftness and ability to hide in the bush" (Castro 20). Moreover, Dobie states that the "Aztecs had a god called Coyotlinauatl...whom they dressed in coyote skins and another being called Tezcalipoca, who was supposed to be able to transform himself into a coyote" (253). Hence, Coyote is deeply embedded in the region we now know as Mexico. Further uses of coyotl as a root for other words specific to this territory and the U.S. Southwest abound: genus of tomato, melon, prickly pear, and other flora all noted for either their medicinal and healing qualities, or the 
appeal they hold for the omnivorous Canis latrans, are all native to the regions either side of the border.

30 It is curious, then, that the purveyor of such "subalterns" across the line which separates two nations-the coyote-should also be barely perceptible in accounts of the lengths Mexican migrants will go to in crossing the border. However, reinstating those elements of Coyoteseemingly lost in the geopolitical obfuscation of the cultural debates that coalesce around the contested territory of the border-to the elusive figure of the coyote reveals the trickster at work in both mundane and mythical ways: a shaper of destinies and identities.

\section{Charles Bowden}

Charles Bowden's dispatches from the low-level militarized conflict at the Mexico-U.S. border should also be considered in relation to the trickster lineage of the coyote, although the connection is not at first apparent. Just as Gerald Vizenor has suggested that Coyote acts both internally within indigenous literatures as a visible element of the characters and externally as a shaper of the ensuing discourse, so too can we perceive this double function in Bowden's own exploration of the culture of coyotaje. This takes the author to the Sonoran Desert and a series of encounters with migrating Mexicans. That Bowden never meets nor converses with any of the coyotes might speak simply of the secretive and clandestine character of their work or their supposed brutality and links to other illicit activities carried out back and forth across the border by organized crime syndicates, but the author's blunt, bellicose, and confrontational prose style does not seem to be the voice of an individual who would fear meeting such characters. Rather, could not coyote's very absence from the detail of the narrative denote the presence of Coyote, as Linscott-Ricketts argues, as an ever-present "creator of the world-as-it-is" (qtd. in Dobie 21)? Such elusiveness on the part of the coyote speaks directly to the intangible nature of Coyote. Such intangibility is applicable to the ambiguous nature of Coyote: is this figure a heroic, comic, or tragic figure; a selfish or moral character; human or animal; male or female; wise or stupid? Coyote defies such categorizations and binary hierarchies of meaning and so too do the coyotes in both their moral ambiguity and in their attempted elimination of the hierarchy the border imposes. One such example occurs when Bowden describes the would-be-migrant's situation in a temporary residence on their journey known as a "flophouse": "Men with quick eyes look you over, the employees of coyotes, people smugglers...now you are a pollo, a chicken, and you need a pollero, a chicken herder" (4). Such allusions to livestock in the common parlance of the people-smuggling business clearly recall several of Thomas King's own articulations of the myths of Coyote (not least "The One about Coyote and the Ducks") and therefore similarly recall the ambivalence of the trickster and the moral dubiousness of the coyote. 
Amalgamating both tropes herein and reading them alongside other observations made by Bowden-such as the suggestion that coyotes "in Mexico now earn at least $\$ 10$ billion a year" (8)-emphasize the ambivalence and ambiguity that the two figures demonstrate and their often fundamentally motivating material desires. As Paul Radin notes, the character of Coyote

[w]ills nothing consciously...knows neither good nor evil yet is responsible for both...[h]e possesses no values, moral or social, is at the mercy of his passions and appetites, yet through his actions all values come into being. (xxii)

This overtly detached view ascribed to Coyote meets its counterpart in the Mexican coyote, who is well aware that many of the "pollos" will be captured, deported, or simply die in their pursuit of work and wages in the United States. An amalgamation of Coyote and coyote epitomizes the negotiated positions that are subject to, and in existence beyond or between, the hierarchies of both the border and the identities that are founded there.

3з Despite this lack of a first-hand account of an encounter with a coyote, the author acknowledges the guiding hand that they always seem to have in the negotiation of the treacherous terrain encountered on the arduous journey from Mexico into the United States: "The top coyote remains in the shadows," Bowden writes, "an intelligent, cunning and mysterious figure" (12). The coyote's shadow here extends, not only over the anonymous migrant's progress from one side of the border to the other, but also into the realm of the negotiated identity formation of their "pollos," and further in this regard into the territory of the mythological Coyote once more. Bowden traces his subject's exodus from the flophouse and closer to the border:

There's a dirt road a short ways to the north. The pollos have walked two days to reach this spot to meet smugglers who've brought American clothing so they will look normal. They rapidly strip naked-bras, panties, blouses, shirts-everything is cast aside. (13)

Here the mundane melds with the mythical as the everyday coyotaje provided by the coyote combines with the transformative powers offered by Coyote. The matter-of-fact action of the "pollos" as they divest themselves of their clothes-and the similarly dispassionate reporting of their actions-belie, once again, the presence of Coyote the trickster, not just in the deception that this almost ritualistic shedding of one's identity and adoption of another will hope to enact, but also in the ways in which this superficial change, when read more deeply, epitomizes Coyote's status as a bricoleur.

35 Again, scholars of the Native American and First Nations, rather than Mesoamerican, embodiment of Coyote have noted this facet of the figure's character, lost amidst the predominantly "illegal" and "criminal" portrayals of the coyote. For example, Ramsey has suggested that Coyote represents "a sort of mythic handy-man who 'cobbles' reality in the form of a bricolage out of the available material" (qtd. in Bright 35). The material available to the coyotes in the Mexican border region may well fall short of the mythical, magical powers of Coyote, 
but the reality that their bricolage seeks to create is one that is designed to assist in illegally entering another nation and further epitomizes the constantly shifting identity politics at play in the borderland. Furthermore, this is not the only conversion that coyotes, when cast as Coyote, might effect, since "trickster frequently is also a transformer...whose accomplishments may include...the teaching of cultural skills" (Bright 35). Here, the de-stratification inherent in coyote cartography intersects with the predominant geopolitical reading and positioning of undocumented migration discourse. This theoretical stance-reading across and between borders along a nomadic relaymirrors "the circuits of capital and labor under late-twentieth century globalization" that the fluidity of migratory identity is intertwined with and implicated in and that coyotes prey upon and profit from (Carminero-Santangelo 161). Carminero-Santangelo posits that this circuitous trajectory "creat[es] deeply entrenched migration patterns...'assimilating' indigenous peoples to 'American' ways of life before they have even arrived in the United States" (161). As a significant powerbroker in this shifting political and cultural landscape, coyotes play an integral role in this "assimilating" process, negotiating not only the physical border but also the wider local-global nexus of regional identities. In this sense, the coyotaje-the evasion of border bureaucracy-takes on this other Coyote characteristic, imparting the "cultural skills" deemed helpful in crossing the border and in remaining successfully on the other side of this boundary.

36 Is the "assimilation" which Carminero-Santangelo identifies even a possibility for the undocumented migrant? Is it an effective tactic for the coyote to impart and the "pollo" to enact? Whilst in Bowden's account, the teaching of cultural skills which the trickster Coyote performs is crucial in gaining access to the United States, to what extent is that performance a reflection of an ongoing reality? Bowden relates one incident of coyotaje:

The man sent a guide to bring him across the river. He spent two days in the coyote's house waiting. Then the man came and said, Put on this soccer uniform. The man said, if the Border Patrol agent asks you where you are going, you say, "San Antonio." If they ask you if you have papers, you say, "Yes," in English. They practiced these simple answers. Then they rode up to the U.S. checkpoint. The Border Patrol agent asked the two questions, got his answers and waved them through. In San Antonio, the coyote took back the soccer uniform. The coyote has pulled the same stunt at least 50 times in the past year at the same checkpoint ...

[h]e never fails. (7)

This performance of identity seems as temporary as the various territories in which the undocumented migrants are required to locate themselves in on their journey. Identity here is de- and re-territorialized at every turn: for the migrants as they perform "citizenship" before becoming "illegal" once more; and for the coyote who temporarily becomes the trickster before returning once more to the shadows of the geo-political battleground of the border. Yet, in both cases, we can read the re-emergence of the Mesoamerican mythology of Coyotlinauatl and this Aztec god's ability to transform itself through the wearing of skins 
and masks, to pass itself off, through mimicry, as something other than itself.

${ }_{38}$ Such strategies are aligned with the comparative knowledge that coyote cartography makes possible since they reveal the shared history of coyote and Coyote as pan-American figures who might enable us to interrogate the ramifications of transnational identities and, concurrently, approach regionalism more critically. Both versions of Coyote are key textual and political operatives in the fictions and frictions of North American border regions. Utilizing these tropes as both objects of analysis and critique, and as shapers of methodological approaches to such tropes, reveals the interconnectedness of the margins of nations and the marginalized voices which occupy such zones. Both Thomas King and Charles Bowden's wider oeuvre could be further interrogated through such a lens. The breadth of texts which detail the exploits of tricksters and smugglers-in indigenous storytelling, literary non-fiction, histories, and journalism-suggest that approaching such materials produced by others outside the scope of this essay, via coyote cartography, will enhance an understanding of the shared histories and cultures of North American regions, producing a map which challenges those of nation-states, dominant cultures, and academic canons and disciplines.

\section{BIBLIOGRAPHY}

Bowden, Charles. "Exodus: Border-Crossers Forge a New America: Coyotes, Pollos, and the Promised Van." Mother Jones. 2006. Web. 10 Sept. 2013. $<$ www.motherjones.com/politics/2006/09/exodus-border-crossers-forge-newamerica>.

Bright, William. A Coyote Reader. Oxford: U of California P, 1993. Print.

Campbell, Neil. The Rhizomatic West: Representing the American West in a Transnational, Global, Media Age. Lincoln: U of Nebraska P, 2008. Print.

Carminero-Santangelo, Marta. "Narrating the Non-Nation: Literary Journalism and 'Illegal' Border Crossings." Arizona Quarterly 68.3 (2012): 157-76. Print.

Castro, Rafaela. Chicano Folklore: A Guide to the Folktales, Traditions, Rituals and Religious Practices of Mexican Americans. Oxford: Oxford UP, 2000. Print.

Colebrook, Clare. "Deterritorialization." The Deleuze Dictionary. Ed. Adrian Parr. New York: Columbia UP, 2005. 66-67. Print.

Comer, Krista. "Introduction: Assessing the Postwestern." Western American Literature 48.1/2 (2013): 3-15. Print. 
Davidson, Arnold E. Coyote Country: Fictions of the Canadian West. London: Duke UP, 1994. Print.

Deleuze, Gilles, and Félix Guattari. A Thousand Plateaus: Capitalism and Schizophrenia. London: Bloomsbury, 2008. Print.

Dobie, Frank J. The Voice of the Coyote. Lincoln: U of Nebraska P, 1961. Print.

Eigenbrod, Renate. Travelling Knowledges: Positioning the Im/Migrant Reader of Aboriginal Literatures. Winnipeg: U of Manitoba P, 2005. Print.

Foster, Tol. "Of One Blood: An Argument for Relations and Regionality in Native American Literary Studies." Reading Together: The Native Critics Collective. Ed. Craig S. Womack et al. Norman: U of Oklahoma P, 2008. 265-302. Print.

Frampton, Kenneth. "Towards a Critical Regionalism: Six Points for an Architecture of Resistance." Postmodern Culture. Ed. Hal Foster. London: Pluto, 1983. 16-30. Print.

Hyde, Lewis. Trickster Makes This World: Mischief, Myth and Art. New York: Farrar, Strauss and Giroux, 1998. Print.

Jones, Karen. "From Big Bad Wolf to Ecological Hero: Canis Lupus and the Culture(s) of Nature in the American-Canadian West." American Review of Canadian Studies 40.3 (2010): 338-50. Print.

Kaplan, Caren. Questions of Travel: Postmodern Discourses of Travel. London: Duke UP, 1996. Print.

King, Thomas. "Borders.” One Good Story, That One. Toronto: Harper Collins, 1993. 129-45. Print.

- The Truth About Stories: A Native Narrative. Minneapolis: U of Minnesota P, 2003. Print.

Kroetsch, Robert, Shirley Neuman, and Robert Wilson. Labyrinths of Voice: Conversations with Robert Kroetsch. Edmonton: NeWest, 1982. Print.

Lionnet, Françoise, and Shu-Mei Shih. Minor Transnationalism. Durham: Duke UP, 2005. Print.

Macpherson, Heidi Slettedahl. "Coyote as Culprit: The Coyote Aesthetics of Gail Anderson-Dargatz's The Cure for Death by Lightning."British Journal of Canadian Studies 17.2 (2004): 175-87. Print.

Martinez, Rubén. Crossing Over: A Mexican Family on the Migrant Trail. New York: Metropolitan, 2001. Print.

McLeod, Neal. Cree Narrative Memory: From Treaties to Contemporary Times. Saskatoon: Purich Publishing. 2009. Print.

Michaelson, Scott, and David E. Johnson. Border Theory: The Limits of Cultural Politics. London: U of Minnesota P, 1997. Print.

New, William Herbert. Borderlands: How We Talk about Canada. Vancouver: UBC Press, 1993. Print.

Pérez-Torres, Rafael. "Chicano Culture Reclaiming Our America: Coyotes at the Border.” American Literature 67.4 (1995): 815-24. Print. 
Peters, Laura. "Thomas King and Contemporary Indigenous Identities." Beyond the Borders: American Literature and Post-Colonial Theory. Ed. Deborah L. Madsen. London: Pluto, 2003. 195-206. Print.

Radin, Paul. The Trickster: A Study in American Indian Mythology. New York: Shocken, 1972. Print.

Reder, Deanna. “Preface.” Troubling Tricksters: Re-Envisioning Critical Conversations. Ed. Deanna Reder and Linda M. Morra. Waterloo: Wilfrid Laurier UP, 2010. vii-ix. Print.

Sadowski-Smith, Claudia. Border Fictions: Globalization, Empire, and Writing at the Boundaries of the United States. Charlottesville: U of Virginia P, 2008. Print.

Saldívar, José David. The Dialectics of Our America: Genealogy, Critique and Literary History. Durham: Duke UP, 1991. Print.

Smith, Carlton. Coyote Kills John Wayne: Postmodernism and Contemporary Fictions of the Transcultural Frontier. Hanover: UP of New England, 2000. Print.

Spener, David. Clandestine Crossings: Migrants and Coyotes on the TexasMexico Border. Ithaca: Cornell UP, 2009. Print.

Vizenor, Gerald. Narrative Chance: Postmodern Discourse on Native American Indian Literatures. Albuquerque: U of New Mexico P, 1992. Print.

\section{ABSTRACTS}

This article develops and deploys critical regionalism as a theoretical framework that enables a comparative transnational critique of North American border regions. Taking its lead from developments in the field of Postwestern Studies it incorporates critical metaphors drawn from Deleuzian philosophy in the form of nomadism and nomadic thought. Examining the nomadic traits of Coyote (the trickster) and coyote (the people smuggler), the article develops a comparative literature approach that challenges the centrality of existing discursive constructions of borders in North America as well as the disciplinary borders of "American" Studies. Through readings of depictions of Coyote and coyote in the work of Thomas King and Charles Bowden, the article suggests ways in which developing dialogue between the Mexican and Canadian borders can avoid the tendency to collapse regionalism into nationalism and respond to calls for more hemispheric approaches to the discipline.

\section{INDEX}

Keywords: borders, coyote (smuggler), Coyote (trickster), Critical regionalism, nomadic thought, nomadism

\section{AUTHOR}

\section{CALEB BAILEY}

University of Nottingham 